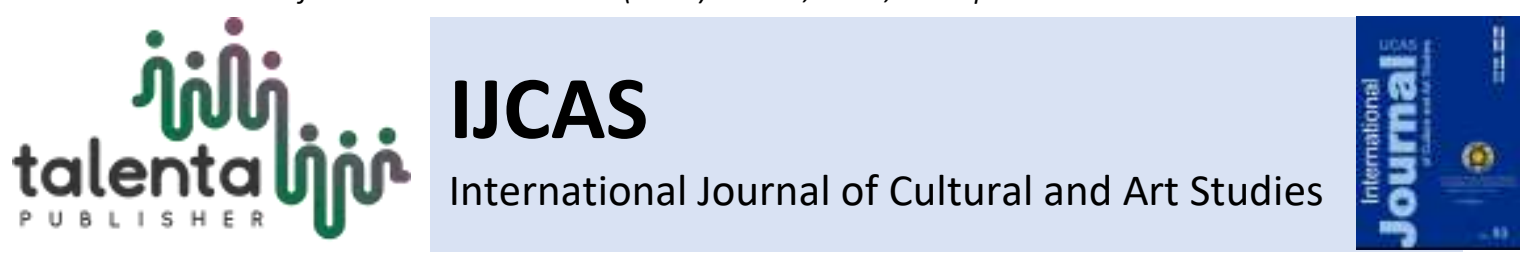

\title{
Contrastive Analysis between Chinese and Indonesian Phonology and Implementation on Conversation Class
}

\author{
Aprilia Ruby Wikarti ${ }^{*}$, Elizabeth Renata ${ }^{2}$, Silvia Moira ${ }^{3}$ \\ 1,2,3 Mandarin Language Education Study Department, Faculty of Languages and Arts, State University of \\ Jakarta, Indonesia
}

\begin{abstract}
This study aims to find out the phonological characteristics of Indonesian Language and Mandarin language, their impact and application in learning Chinese conversations. This study will use descriptive comparative methods and surveys. Based on the data obtained, there are differences in the pronunciation of single Indonesian and Chinese vowels, namely vowel [y], [y], [i]. Mandarin has triftong, which is [iou], [iao]. The consonants of Indonesian and Mandarin have similarities, but the pronunciation is different. The consonant of Indonesian is not distinguished from no aspirations and aspirations, based on no voices and voices. In suprasegmental features, such as tons, intonation, pressure, pauses, Mandarin is one of the tonal languages, whereas Indonesian is not a tonal language. In Indonesian, the pressure functions to distinguish meaning in the sentence level, but does not distinguish meaning at the word level. Whereas in Mandarin, the pressure is divided into word pressure and sentence pressure. In Indonesian, intonation plays an important role when distinguishing the meaning of sentences. Whereas in Mandarin, the rules for pronunciation of intonation are not strict. Pause in Indonesian and Mandarin, marked by the use of signs. The results of this study can help teachers determine and use appropriate learning techniques so that they can help, facilitate the needs, demands, and goals of students in pronunciation.
\end{abstract}

Keywords: Contrastive Analysis, Phonology, Mandarin, Conversation.

Received 06 September 2019 | Revised 19 September 2019| Accepted 28 September 2019

\section{Introduction}

Language is a combination of sound and meaning. One of language function is as a communication tool. Language is used to express one's intensions, opinions which conveyed through certain sound systems. In communication, improper pronunciation can cause misunderstanding or even unable to understand other parties speech.

Each language has its own system and structure. Learning a language must master the language sound system. Phonological studies are divided into two things, phonology and phonetics.

\footnotetext{
* Corresponding author at: Mandarin Language Education Study Department, Faculty of Languages and Arts, State University of Jakarta, Indonesia

E-mail address: apriliarubyw.s@unj.ac.id
} 
Phonology discussed the function, behavior, and organization of sound as an element of linguistics [1]. Phonetics is a branch of linguistics that studies sounds of human speech [2]. That sound can have meaning, it can also have no meaning. In foreign language learning as a second language, phonetics mastery can be said to be the basis of learning [3]. If students have a good phonological basic, it is expected to encourage the effectiveness of language learning.

Mandarin language includes elements of vocabulary, grammar, and phonological [4]. The pronunciation standard for learning Mandarin is Beijing pronunciation. In learning process, mastering Beijing's standard pronunciation is not easy. There are some factors that become obstacles, it can come from the teacher and students such as the perspective and habits of the learning process. But it can also come from external factors. Lack of knowledge and ability, difficulty level of pronunciation can also cause difficulties in mastering Mandarin phonology.

If difficulty factors in learning phonology can be known, it is expected to find a way to facilitate mastering Mandarin language. In the learning process, teacher is expected to facilitate and master good learning techniques so that they can help students' difficulties in conversation class.

Research on the contrastive analysis between Mandarin language phonology and Indonesian language phonology has been done before, both related to learning strategies or not. Researchers listed various suggestions that hopefully can improve student competency in Mandarin language pronunciation, among them is the emphasis the use of Hanyu Pinyin spelling to represent sounds in Mandarin language, the use of fingers to learn the difference of pronunciation tones.

This research aims to obtain detailed description about the characteristics of Mandarin language and Indonesian language phonology, also to observe application the knowledge of phonology in learning Mandarin language conversation for students of Mandarin Language Education Department, Faculty of Languages and Arts, State University of Jakarta.

\section{Mandarin Language Phonology Teaching}

Zhou and Li [5] stated at the early level, the emphasis of learning is imitating sounds. If students are able to understand correctly, it will be able to distinguish sounds. Further explained that phonology learning is not only learning phonology knowledge, but it is closely related to learning and training in listening and conversation skills. The learning objectives are students correctly listening and reciting sounds, and being able to master the spelling of Hanyu Pinyin. The basic of pronunciation learning is start with mastering a single syllable sound, continuing to the sentence. There are 400 more syllables in Mandarin language [6]. 
Phonological learning in Mandarin language is the basic for teaching Mandarin as a foreign language. Students with teacher guidance, within a limited time try to understand and then master Mandarin language pronunciation. In Mandarin language pronunciation learning, there are several things that must be considered, namely: focusing on imitating, from simple to complex, from old things to new things, paying attention to difficult things, using a combination of learning techniques, constantly refining pronunciation errors.

Mandarin language is written in Han characters. The script includes the form and sound, but the form of Han characters is very difficult to be used as a sound standard, so that sound learning is a very important thing.

\subsection{Hanyu Pinyin}

Han characters is not the type of script that represents sound. In the 1950s the Chinese government compiled the alphabetical spelling to represent the pronunciation of Han characters, the spelling was called Hanyu Pinyin [7]. This spelling uses the letters of the Roman alphabet as the basis. The pronunciation standard used as a reference is the Beijing pronunciation. This spelling can help teachers and students whose native language or first language use the letters of the Roman alphabet. Luo and Wang [8] stated that there is no, there is not even a language capable of representing all sounds in all languages in the world. There is no script that can show all sounds in all languages in the world. But despite this opinion, the spellings compiled by the Chinese government and foreign parties are to make it easier for people to learn and master Mandarin language. The spelling of Hanyu Pinyin, can help students distinguish and pronounce sounds. This can be useful to provide a basic understanding of Mandarin language pronunciation also makes it easier for students to communicate using Mandarin language.

According to Jin [9], there are several spelling functions of Hanyu Pinyin, namely:

(1) Representing the sound of Han characters. The spelling of Hanyu Pinyin has been through a scientific process so that the spelling is more advanced than the previous spellings that have been used.

(2) Spreading Mandarin language. Hanyu Pinyin spelling is a simple and precise symbol system to represent the sound of Mandarin language. The spelling of Hanyu Pinyin can help foreigners and Chinese dialect speakers to learn and master the sounds of Mandarin language.

(3) Improve children's language and logical skills. The form of Han script is very complicated, difficult to learn and to remember. The focus of language learning on elementary school students from $1^{\text {st }}$ grade to $2^{\text {nd }}$ grade in China is make the students 
familiar with Han characters, it is difficult to carry out reading and writing learning. This resulted in the ability of $3^{\text {rd }}$ grade elementary school students in China to be similar to the ability of $1^{\text {st }}$ grade elementary school students in a country that uses the spelling of Hanyu Pinyin to learn Han characters. In early 1982 spelling usage of Hanyu Pinyin was developed in learning Mandarin language in China, especially in reading and writing skills.

(4) Make it easy to enter data and information into computers, such as dialect characters, names of people, places, scientific terms, etc.

In Hanyu Pinyin spelling there are vowel and final terms, consonants and initials, tones, pronunciation break. 26 Roman alphabet letters used in the spelling of Hanyu Pinyin.

\section{Mandarin and Indonesian Language Phonology Characteristics Comparison}

\subsection{Vowels}

Indonesian language has 6 single vowels: [a], [o], [e], [ə], [i], [u] and 3 diphtongs: [ai], [au], [ou]. Mandarin language has 7 single vowels: [a], [o], [e], [y], [i], [u], [y]. 9 diphtongs: [ai], [ei], [ao], [ou], [ia], [ie], [ua], [uo], [ye] and 4 triphtongs: [iao], [iou], [uai], [uei].

The following is a comparison of Mandarin and Indonesian Language vowels based on:

(1) The position of the tongue:

Table 1. A comparison of Mandarin and Indonesian Language vowels based on the position of the tongue.

\begin{tabular}{lcccc}
\hline \multicolumn{1}{c}{ Position of the tongue } & \multicolumn{2}{c}{ Mandarin Language } & \multicolumn{2}{c}{ Indonesian Language } \\
\cline { 2 - 5 } & Round & Not Round & Round & Not Round \\
\hline Apex & & & {$[\mathrm{i}],[\mathrm{e}]$} \\
Laminal & {$[\mathrm{y}],[\mathrm{u}],[\mathrm{o}]$} & {$[\mathrm{i}],[\mathrm{e}],[\mathrm{a}],[\mathrm{\gamma}]$} & & {$[\mathrm{\jmath}],[\mathrm{a}]$} \\
Dorsum & & & {$[\mathrm{u}],[\mathrm{o}]$} & \\
\hline
\end{tabular}

(2) Structure:

Table 2. A comparison of Mandarin and Indonesian Language vowels based on structure.

\begin{tabular}{lcc}
\hline Structure & Mandarin Language & Indonesian Language \\
\hline High (close) & {$[\mathrm{i}],[\mathrm{y}],[\mathrm{u}]$} & {$[\mathrm{i}],[\mathrm{u}]$} \\
Half high (half close) & {$[\mathrm{\gamma}],[\mathrm{o}]$} & \\
Middle & & {$[\mathrm{e}],[\mathrm{o}],[\mathrm{\jmath}]$} \\
Half low (half open) & {$[\mathrm{e}]$} & \\
Low (open) & {$[\mathrm{a}]$} & {$[\mathrm{a}]$} \\
\hline
\end{tabular}


Sound elements can be divided into two major parts, namely vowels and consonants. In Mandarin, vowels are an important part. All Hanyu Pinyin spelling must have vowels. There is even a spelling that only consists of single vowels. Mandarin language vowel phonemes consist of / a /, / o /, / e /, / a /, / i /, / / /, / /, / u /, / ü / [2d]. Whereas according to Liu [10], Mandarin language vowel phonemes consist of / a /, / o /, / y /, / ع /, / ə/, / i /, / / /, / //, / u /, / ü /. But the phonemes in Hanyu Pinyin spelling are only represented by 7 phonemes, namely /a/, /o/, /e/, /i/, /u/, /ü/, /er/. The letter /e/ represents 2 sounds /e/ and /ə/. Whereas the letter /i/, represents 3 sounds:

(1) /i/ if follow consonants b, p, m, d, t, n, l, j, q, x

(2) $/ \mathrm{q} /$ if follow consonants $\mathrm{z}, \mathrm{c}, \mathrm{s}$

(3) $/$ / if follow consonants zh, ch, sh, r

In Mandarin language, also know the term "final", is a syllable after an inisial (the term of inisial is explain at next part). Final can be one or more vowels. From the type, final component in Mandarin language consists of three types [11], namely:

(1) Single final is a final that consist of one vowel.

"ma", "m" followed single final "a".

(2) Plural final is a final that consist of two or three vowels.

If plural final structure consist of two vowels, the structure divide in to front and back vowel. There are two types of two vowels final structure:

Front vowel loud: [ai], [ei], [au], [ou]

Back vowel loud: [ia], [ie], [ua], [uo], [ye]

For example:

"mai", "m" followed by plural final "ai".

"mie", "m" followed by plural final "ie".

If plural final structure consists of three vowels, the structure divide in to front, middle, back final. The middle final is the main vowel; the sound is the loudest, most obvious. For example:

"miao" "m" followed by plural final "iao".

(3) Nasal sound final is a final, which consists of one or two vowels followed by nasal sound $[\mathrm{n}]$ or $[\mathrm{n}]$.

"min" "m" followed by nasal final "in".

"ming" "m" followed by nasal final "ng". 


\subsection{Consonants}

There is equation among Mandarin language and Indonesian language consonants. However, even though it has the same consonants, the pronunciation are not the same. This is caused by differences in articulators and ways to articulate. In Indonesian, consonants are not distinguished from unaspirated and aspirated, but based on voice and voiceless.

The following is a comparison of Mandarin and Indonesian Language consonants based on:

(1) Ways to articulate:

Table 3. A comparison of Mandarin and Indonesian Language consonants based on ways to articulate

\begin{tabular}{|c|c|c|c|c|}
\hline \multirow{2}{*}{$\begin{array}{l}\text { Ways to } \\
\text { articulate }\end{array}$} & \multicolumn{2}{|c|}{ Mandarin Language } & \multicolumn{2}{|c|}{ Indonesian Language } \\
\hline & Unaspirated & Aspirated & Voiceless & Voice \\
\hline Plosive & $\mathrm{b}[\mathrm{p}], \mathrm{d}[\mathrm{t}], \mathrm{g}[\mathrm{k}]$ & $\begin{array}{l}\mathrm{p}\left[\mathrm{p}^{\prime}\right], \mathrm{t}\left[\mathrm{t}^{\prime}\right], \mathrm{k} \\
{\left[\mathrm{k}^{\prime}\right]}\end{array}$ & $\begin{array}{l}\mathrm{p}[\mathrm{p}], \mathrm{t}[\mathrm{t}], \mathrm{k}[\mathrm{k}], \mathrm{kh} \\
{[\mathrm{x}]}\end{array}$ & $\mathrm{b}[\mathrm{b}], \mathrm{d}[\mathrm{d}], \mathrm{g}[\mathrm{g}]$ \\
\hline Fricative & $\begin{array}{l}\mathrm{f}[\mathrm{f}], \mathrm{s}[\mathrm{s}], \text { sh }[\mathrm{s}], \mathrm{x} \\
{[\mathrm{c}], \mathrm{h}[\mathrm{x}]}\end{array}$ & $\mathrm{r}[\mathrm{z}]$ & $\begin{array}{l}\mathrm{f}[\mathrm{f}], \mathrm{s}[\mathrm{s}], \mathrm{sy}[\mathrm{f}], \mathrm{h} \\
{[\mathrm{h}]}\end{array}$ & $\mathrm{v}[\mathrm{v}], \mathrm{z}[\mathrm{z}]$ \\
\hline Affricate & $\mathrm{z}[\mathrm{ts}], \mathrm{zh}[\mathrm{ts}], \mathrm{j}[\mathrm{t} 6]$ & $\begin{array}{l}\mathrm{c}\left[\mathrm{ts}^{\prime}\right], \mathrm{ch}\left[\mathrm{ts}^{\prime}\right], \mathrm{q} \\
{\left[\mathrm{tc}^{\prime}\right]}\end{array}$ & $c[t]]$ & $\mathrm{j}$ [d] \\
\hline Nasal & $\mathrm{m}[\mathrm{m}], \mathrm{n}[\mathrm{n}], \mathrm{ng}[\mathrm{y}]$ & & & $\begin{array}{l}m[\mathrm{~m}], \mathrm{n}[\mathrm{n}], \mathrm{ng} \\
{[\mathrm{n}], \text { ny }[\mathrm{n}]}\end{array}$ \\
\hline $\begin{array}{l}\text { Lateral } \\
\text { approctimant }\end{array}$ & & $1[1]$ & $1[1]$ & \\
\hline Retloflex & & $\mathrm{r}[\mathrm{r}]$ & & \\
\hline Approctimant & & $w[w], y[j]$ & & \\
\hline
\end{tabular}

When compared Mandarin language and Indonesian language consonants, there are 19 consonants are the same, namely b, c, d, f, g, h, j, k, 1, m, n, p, r, s, t, w, y, z, ng [y]. However, between these consonants there are only 7 consonants that have pronunciation similarities, namely f, 1, m, n, s, w, ng [y]. Whereas 12 other consonants have different pronunciation. Even different ways of articulating, consonant examples $r$.

(2) Articulators:

Table 4. A comparison of Mandarin and Indonesian Language consonants based on articulate

\begin{tabular}{llll}
\hline \multicolumn{2}{c}{ Artikulator } & \multicolumn{1}{c}{ Mandarin Language } & \multicolumn{1}{c}{ Indonesian Language } \\
\hline Bilabial & & $\mathrm{b}[\mathrm{p}], \mathrm{p}\left[\mathrm{p}^{\prime}\right], \mathrm{m}[\mathrm{m}]$ & $\mathrm{b}[\mathrm{b}], \mathrm{p}[\mathrm{p}], \mathrm{m}[\mathrm{m}], \mathrm{w}[\mathrm{w}]$ \\
Dental & Labio dental & $\mathrm{f}[\mathrm{f}]$ & $\mathrm{f}[\mathrm{f}], \mathrm{v}[\mathrm{v}]$ \\
& Apiko dental & $\mathrm{s}[\mathrm{s}], \mathrm{z}[\mathrm{ts}], \mathrm{c}\left[\mathrm{ts}{ }^{\prime}\right]$ & \\
\multirow{2}{*}{ Alveolar } & Lamino alveolar & & $\mathrm{d}[\mathrm{d}], \mathrm{s}[\mathrm{s}], \mathrm{t}[\mathrm{t}], \mathrm{z}[\mathrm{z}], \mathrm{n}[\mathrm{n}], 1[\mathrm{l}], \mathrm{r}[\mathrm{r}]$ \\
& Apiko alveolar & $\mathrm{d}[\mathrm{t}], \mathrm{t}\left[\mathrm{t}^{\prime}\right], \mathrm{n}[\mathrm{n}], 1[\mathrm{l}]$ &
\end{tabular}




$\begin{array}{llll}\text { Palatal Lamino palatal } & \mathrm{x}[\mathrm{c}], \mathrm{j}[\mathrm{tc}], \mathrm{q}\left[\mathrm{t} \mathrm{t}^{\prime}\right] & \mathrm{c}[\mathrm{t}] \mathrm{j}, \mathrm{j}[\mathrm{d}], \mathrm{sy}[\mathrm{f}], \mathrm{ny}[\mathrm{n}], \mathrm{y}[\mathrm{j}] \\ & \text { Apiko palatal } & \mathrm{zh}[\mathrm{ts}], \mathrm{ch}\left[\mathrm{tg} \mathrm{s}^{\prime}\right], \operatorname{sh}[\mathrm{s}], \mathrm{r}[\mathrm{z}] & \\ \text { Dorso velar } & \mathrm{g}[\mathrm{k}], \mathrm{k}\left[\mathrm{k}^{\prime}\right], \mathrm{h}[\mathrm{h}], \mathrm{ng}[\mathrm{y}] & \mathrm{g}[\mathrm{g}], \mathrm{k}[\mathrm{k}], \mathrm{kh}[\mathrm{x}], \mathrm{ng}[\mathrm{y}] \\ \text { Glotal } & & \mathrm{h}[\mathrm{h}]\end{array}$

Wang and Lin [12] stated Mandarin language has 22 consonants, there are single consonants and plural consonants, namely $b[\mathrm{p}], \mathrm{p}\left[\mathrm{p}^{\prime}\right], \mathrm{m}[\mathrm{m}], \mathrm{f}[\mathrm{f}], \mathrm{d}[\mathrm{t}], \mathrm{t}\left[\mathrm{t}^{\prime}\right], \mathrm{n}[\mathrm{n}], \mathrm{l}[\mathrm{l}], \mathrm{g}[\mathrm{k}], \mathrm{k}\left[\mathrm{k}^{\prime}\right], \mathrm{h}[\mathrm{h}], \mathrm{j}[\mathrm{t} c]$, $\mathrm{q}\left[\mathrm{tg}{ }^{\prime}\right], \mathrm{x}[\mathrm{c}], \mathrm{r}[\mathrm{z}], \mathrm{s}[\mathrm{s}], \mathrm{z}[\mathrm{ts}], \mathrm{c}\left[\mathrm{ts}^{\prime}\right], \mathrm{zh}[\mathrm{ts}], \mathrm{ch}\left[\mathrm{ts}{ }^{\prime}\right], \mathrm{sh}[\mathrm{s}]$. In addition to consonant forms, there is still one form, namely ng $[\mathrm{y}]$. However, this $[\mathrm{y}]$ can only be placed at the end.

In Mandarin, beside consonant, also known "initial" terms. The initials in Mandarin language phonetics are consonants that located at the beginning of Hanyu Pinyin syllable. When viewed from number of consonants, there are 21 initials in Mandarin. [ $\mathrm{y}$ ] cannot be the initial component.

Mandarin language also recognizes the term "empty initials", where the first component of a Hanyu Pinyin syllable is a vowel, for example: [an], [ən]. The syllables do not have consonants as inisial at the beginning, so they are called "empty initials".

\subsection{Suprasegmental Characteristics}

This research discusses some suprasegmental characteristics, such as tones, intonation, stress, pronunciation break. First, we will discuss about tones. Mandarin is one of the tonal languages in the world. Tone in Mandarin determines speech meaning. There are 5 tones in Mandarin, written in 4 codes: -, /, , I, while neutral tone don't have code.

\begin{tabular}{|lllll|}
\hline High & 5 & 5 & 5 & 5 \\
Half High & 4 & 4 & 4 \\
Middle & 3 & 3 & 3 \\
Half Low & 2 & 2 & 2 \\
Low & 1 & 1 & 1
\end{tabular}

Figure 1. Mandarin Language Tones [13]

Tones codes writing in Hanyu Pinyin has its own rules. The code is placed on top of the final syllable, above the vowels which when the pronunciation is the loudest, for example: lái, tóu. In the syllable "lái and tóu" there are double finals "ái and óu". In the two double finals, the vowels "a and o" are the loudest when reciting so the ton code is placed on it. 
Basically this tone codes are unchangeable, but in certain conditions it can change. If two syllables Hanyu Pinyin two tones of "shang sheng", the first component of Hanyu Pinyin change into "yang ping". Example: "měihăo" becomes "méihăo".

Besides using the codes above, there is another way to write codes, is using numbers 1 through 5. The numbers are represent tones sound level (see picture 1). Number 55 represents flat tone or "yin ping", number 35 represents up tone of up or "yang ping", number 214 represents down go up or "shang sheng", and number 51 represents down tone or "qu sheng".

It stated above that Mandarin is a tonal language, it has rules about tones. But Indonesian language is not a tonal language, so has no rules stated about tones. There is no discussion about tone in Indonesian suprasegmental characteristics.

Second, intonation. Mandarin is a tonal language, so the sentence intonation rules are not strict as tonal rules. For example, a question sentence does not pay much attention on how to pronounce the intonation. However, more attention is paid to the use of question marks in the sentence. In Mandarin language, question sentence can be pronounced using $1^{\text {st }}$ tone, $2^{\text {nd }}$ tone, or $4^{\text {th }}$ tone. If the question sentence does not use a question mark, then the sentence can be pronounced with $2^{\text {nd }}$ tone. If the sentence is pronounced using $1^{\text {st }}$ tone or $4^{\text {th }}$ tone then the sentence becomes a statement sentence.

In Indonesian language, intonation refers to the tone during sentence pronunciation, while rhythm refers to words stressing in a sentence. Although there is intonation, the word pressure is not completely lost. Word pressure only weakens. In Indonesian, the intonation function is not to distinguish meaning, but to show emphasis. For example:

(1) Adik membeli permen di warung.

(2) Adik membeli permen di warung.

The emphasis on the two sentences above is different. In sentence (1) changes in intonation are found in the word warung, while in sentence (2) changes in intonation occur in the word candy. In Indonesian, the pressure serves to differentiate intentions at the level of sentences, but does not distinguish meaning in the level of words [14].

In Indonesian language, stressing functions to distinguish intentions at the level of sentences, but does not distinguish meaning in the level of words. Whereas in Mandarin language, the 
stressing is divided into two things, namely word pressure and sentence pressure. At word stressing, depends on the presence of tons of neutral on the word. Whereas sentence stressing is more generally use, based on logic to convey meaning or feeling.

In Indonesian language, intonation plays an important role when distinguish the meaning of sentences. Whereas in Mandarin language, the pronunciation's intonation rule is not strict. This is because Mandarin emphasizes tone of words and punctuation marks (question marks, exclamation marks, etc.).

Pronunciation break in Indonesian language, marked by the use of signs [15]. This is based on differences in locations, such as pronunciation break in syllables, words, phrases, clauses, sentences and discourses. Just like the emphasis on Mandarin language, pausing in Mandarin language is also distinguished by grammar and logic.

\section{Impacts of Phonological Characteristics on Mandarin Language and Indonesian Language on Conversation Classes}

\subsection{Vocals}

In Indonesian language there are 6 single vowels, namely [a], [o], [e], [ə], [i], [u] and 3 diphthongs, namely [ai], [au], [ou]. Whereas in Mandarin language there are 7 single vowels, namely [a], [o], [e], [y], [i], [u], [y], 9 diphthongs [ai], [ei], [ao], [ou], [ia], [ie], [ua], [uo], [ye] and 4 triphthongs, namely [iao], [iou], [uai], [uei].

Among Indonesian Language and Mandarin Language single vocals, there are similar and different vocals. Based on the results of the questionnaires that have been distributed, most of the respondents did not experience difficulties when reciting similar vocals, but when pronouncing different vocals, for example: vocal [y] vocals most respondents experienced difficulties.

Single vowel [i] has 3 different phonemes, namely / i /, / / /, / / . The pronunciation depends on the initials in front. When reciting the phoneme $/ \mathrm{i} /$, most respondents said they did not experience difficulties, but when pronouncing phonemes / 1 / and / $/$ as in the words [ts1] and [ts '?], most respondents had difficulty. This is related to those initials that are in front of the phoneme, not exist in Indonesian Language. Therefore, that respondents have difficulty finding similar pronunciation in Indonesian Language.

Respondents also stated they have little difficulty when pronouncing vowel [y] in Mandarin Language. Some respondents will pronounce the vowel $[\gamma]$ to be a vowel [e]. This is related to 
vocal pronunciation [e] in Indonesian language. Example: In the word, "tempe" the Indonesian language will pronounce it to be [tempe]. While in Mandarin the syllables "te" and "pe" will be pronounced $\left[t^{\prime} y\right]$ and [ $\left.p^{\prime} \gamma\right]$. This pronunciation in Indonesian language causes errors when pronouncing in Mandarin language.

Indonesian language and Mandarin language also have differences in diphthongs. In terms of numbers, Mandarin language has more diphthongs. Among diphthongs, there are some diphthongs, which are considered more difficult to pronounce, namely [ao], [ou], [uo]. This difficulty is more due to vocal similarities in the diphthongs. So when pronunciation is often exchanged or incorrectly recited.

As mentioned above, Mandarin language has triphthong, while Indonesian language does not. When pronounce triphthong, some respondent's encountered difficulties, such as triphthongs [iou] and [iao]. As with diphthong pronunciation, the vowel resemblance in triphthong also causes pronunciation errors. Besides that in Indonesian language, does not have triphthong. This also causes respondents not to be accustomed to pronouncing triphthong.

\subsection{Consonants}

In Indonesian language there are twenty-three consonants, namely [p], [t], [k], [b], [d], [g], [c], [j], [f], [s], [f], [x], [h], [z], [m], [n], [n], [y], [r], [1], [v], [w], [y ]. Whereas Mandarin language has 22 consonants, there are both single consonants and double consonants, namely $b$ [p], p [p '], m [m], f [f], d [t], t [t'], n [n], l [1], g [k], k [k '], h [h], j [tc], q [t''], x [6], r [z], s [s ], z [ts], c [ts '], zh [ts], ch [ts'], sh [s]. In addition to the twenty-one consonant forms, there is still one form, namely ng $[\mathrm{n}]$. But this $[\mathrm{y}]$ can only be placed at the end.

As explained in the previous section, although there are consonant equations in Indonesian language and Mandarin language. However, the pronunciations are not necessarily the same or similar. This is also has an impact when respondents learn Mandarin language consonants.

Among these Mandarin language single consonants, respondents are more difficult to study consonants: plosive consonants [p '], [k'], [t '], fricative consonants [6], [z], affricate consonant [ts'], [t6' ] For nasal consonants and side by side the respondent said it was easier to learn. With regard to plosive consonants, Indonesian language does not distinguish consonants based on aspirations and not aspirations. This certainly has an effect when reciting aspirated plosive consonants, respondents have a tendency to add consonant $[\mathrm{h}]$. For fricative consonants, the pronunciation [6] is often confused with consonant $[\mathrm{s}]$, whereas the consonant $[\mathrm{z}]$ respondent will tend to pronounce [r]. The pronunciation of affricate consonants [ts '], [t $\mathrm{t}^{\prime}$ ] in Indonesian language are pronounced differently, so that respondents are often confused or wrong. 
Double consonants in Mandarin language also often make it difficult for respondents to recite them, including $\mathrm{zh}$ [ts], ch [ts '], sh [s]. The absence of these consonants in the Indonesian language caused respondents to be unfamiliar and difficult to pronunce.

\subsection{Suprasegmental Characteristics}

Mandarin is a tonal language. The existence of tones in Mandarin language is a challenge for respondents when learning Mandarin language. On the five tones (include neutral tone) in Mandarin language, it was noted that respondents had more difficulty learning $2^{\text {nd }}$ tone and $3^{\text {rd }}$ tone. Referring to the tones table (table 6), there are similarities between the two tones. So that the respondents have a little hampered to master it. As for $1^{\text {st }}$ tone and $4^{\text {th }}$ tone, respondents said it was easier to learn. This affects the pronunciation of words with plural syllables, phrases, clauses, sentences, and discourses that contain $2^{\text {nd }}$ tone and $3^{\text {rd }}$ tone in them.

When reading words, phrases, clauses, sentences, and texts in Mandarin, it is also related to stressing. It means also relate to tones. If the respondents does not mastery tones pronunciations, it will have an impact on stressing.

The other suprasegmental characteristic is intonation. In Mandarin language, intonation does not have as clear and strict rules on Indonesian language, so respondents do not have too much trouble learning it.

Besides three characteristics above, there is pronunciation break. Recitation of pronunciation break related to the respondents knowledge of the meaning of words, phrases, clauses, sentences, and texts. If the respondent does not understand the meaning, then giving a pronunciation break will have difficulties.

\section{Application of Phonological Knowledge in Conversation Classes}

Here are some techniques that can be used to apply phonological knowledge to Mandarin language conversations:

\subsection{Consonants and vowels}

(1) Students listen to recordings of conversations, songs, short videos, or films to get the right examples of consonant and vowel pronunciation;

(2) Students use props in the form of paper or a mirror to train pronunciation of consonants with aspiration and not aspiration; 
(3) Students use hands or props in the form of pictures, photographs or sculptures to understand the articulation tool and the way of articulation, so that can produced the right consonants and vowels;

(4) Students do the exercises in the form of dictation or fill in the blank to see the ability to distinguish consonants and vowels pronunciation;

(5) Students use spelling cards or Hanyu Pinyin tables to show symbols used that represent a consonant and vowel sound;

(6) Students train similar consonants and vowels pronunciation, based on examples prepared by the teacher. Examples can be in the application of languages other than Mandarin language and Indonesian language;

(7) Students imitate the example of consonants and vowels pronunciation not only in the form of words but also in the form of phrases, sentences, texts.

\subsection{Suprasegmental Characteristics}

(1) Students listen to recordings of conversations, short videos, or films to provide examples of appropriate ton pronunciation;

(2) Students practice reciting tons under the guidance of a teacher;

(3) Students use hands or props in the form of pictures, photos, or videos to understand the right high tones of pronunciation;

(4) Students do the exercises in the form of dictation or fill up the blank to see the ability to distinguish tones;

(5) Students use cards of tones to show the tones symbol that used to represent a tone sound;

(6) Students imitate the tones pronunciation not only in the form of words but also in the phrases, sentences, texts;

(7) Students use games to read or speak according to the text that has been prepared. The teacher will correct if there is an error and students are asked to repeat the correction;

(8) Students follow examples of phrases or sentences that show different pronunciation breaks and intonation can determine some meanings.

\section{Conclusion}

Mastery phonology is related to accuracy deliver meaning in conversation. Because Chinese writing is not symbolized by alphabet, which can be arranged into words, phrases, clauses, sentences, or discourse. Mandarin character is a written symbol, and Hanyu Pinyin spelling only as one of tools to master pronunciation of these characters. The limited number of Hanyu Pinyin spelling causes the correct pronunciation of vowels, consonants, and tons become important in 
conversation. If during a conversation has a pronunciation error certainly affects fluency and meaning to be communicate.

Indonesian language and Mandarin language phonological similarities and differences can be an inhibiting factor but can also be a supporting factor for students' mastering Mandarin. It is expected that results of this study, teachers can make similarities and differences characteristics into factors that can help students. Teachers explanations and exercises can help students learning process. In addition, teachers are expected to encourage students to practice continuously. Students Mandarin competency does not only depend on teachers ability and efforts but there must also be efforts from students themselves.

\section{REFERENCES}

[1] R. Lass, Phonology: An Introduction to Basic Concepts. Cambridge: Cambridge University, 1984.

[2] W. O’Grady, J. Archibald, M. Aronoff, and J. Rees-Miller, Contemporary Linguistics: An Introduction 5th ed, 5ed ed. New York: Bedford-St.Martin's, 2005 .

[3] H. Zhang, Hanyu Keyi Zheyang Jiao - Yuyan Yaosu Pian. Beijing: Shangwu Yinshuguan, 2008.

[4] S. Xu, Putonghua Yuyin Changshi. Beijing: Yuwen Chubanshe, 1999.

[5] X. Zhou and H. Li, Duiwai Hanyu Jiaoxue Rumen - The Guidance of Teaching Chinese to Foreigner. Guangzhou: Zhongshan Daxue Chubanshe, 2004.

[6] T. Wu, Putong Yuyanxue Gaiyao. Beijing: Gaodeng Jiaoyu Chubanshe, 2004.

[7] A. Cui, Z. Peng, and Z. Zhou, "Zhou Youguang Dui Hanyu Pinyin De Jiechu Gongxian — Weishenme Renmen Ba Zhou Youguang Jiao Zuo 'Hanyu Pinyin De Baba,"” Jiangxi Kexue Shifan Daxue Xuebao, vol. August, no. No.4, pp. 18$25,2018$.

[8] C. Luo and J. Wang, Putong Yuyinxue Gangyao. Beijing: Shangwu Yinshuguan, 2004.

[9] Y. Jin, Putonghua Yuyin. Beijing: Shangwu Yinshuguan, 2007.

[10] F. Liu, Hanyu Yuyin Xunlian Jiaocheng. Beijing: Beijing Yuyan Daxue Chubanshe, 2006.

[11] F. Xing, Xiandai Hanyu. Beijing: Gaodeng Jiaoyu Chubanshe, 2007.

[12] L. Wang and T. Lin, Yuyin Jiaocheng. Beijing: Beijing Daxue Chubanshe, 2007.

[13] A. Li and A. Cai, "Yinniyu Yu Hanyu Yuyin Duibi Ji Yinni Xuesheng Xide 
Hanyu Yuyin Nandian Fenxi," J. Overseas Chinese Educ., vol. 66, no. 1, pp. 7989, 2013.

[14] M. Muslich, Fonologi Bahasa Indonesia. Jakarta: Bumi Aksara, 2010.

[15] Marsono, Fonetik. Jogjakarta: Gadjah Mada University Press, 1993. 